\title{
Evolving the role of higher education: how to bring inclusive practices into learning
}

\section{Introduction}

The United States Department of Education's mission reads: To promote student achievement and preparation for global competitiveness by fostering educational excellence and ensuring equal access. ${ }^{1}$ are institutions of higher education ensuring equal access, and are they really preparing students for what they call, "global competitiveness"? President Obama and his administration strived for colleges and universities to attract and admit students from various backgrounds, but their main goal was to support and retain these students once they are on their respective college campuses. Although what the administration worked hard for is slowly increasing, there are still continuing educational inequities and gaps in opportunity that continue to create difficulty in obtaining a quality post-secondary education. In order for the United States to retain strength as a world leader in college graduates, it must continue to ensure equitable educational access for a population that is and will continue to increase in diversity.

\section{Purposeful curriculum: engaging students}

College professors are often against the work that it will take to develop a diverse curriculum Lynch ${ }^{2}$ Matthew Lynch states in his article entitled, "Diverse Conversations: Why Curriculum Diversity is a Good Plan" that college learning is more than just obtaining skills, it should be about incorporating truth in what is being talked about to give students a look at where they stand in their chosen fields at this moment in time (2016). Knowledge about diversity allows college students to grasp on to the tools that they will need to manage effectively in the workplaces of today's global society. The main reason that diversity should be added into college curriculums is that it assists to develop empathetic, socially conscious individuals.

There are many arguments that students will learn about their fields through experience. Yes, they will learn more through experience than reading textbooks, however, institutions of higher education should not turn a "blind eye" when they have a great chance of preparing students for the world that awaits them after they walk across the stage. Curricula that engage students continue to create critical thinkers that are aware of what is going on in the landscape of their chosen careers. Lynch states that a curriculum that is purposeful will create a sharp lens for college students that will allow them to view their chosen profession as more than a way to make a living, but it is also an opportunity to stimulate positive change (2016). With students from different cultural backgrounds continuing to grace their presences on college campuses, the Eurocentric teaching focus has made it difficult for students from different races, and even socio-economic statuses to do anything to counter the dynamic at hand.

Overwhelming climate: getting prepared, involved, and adapted

According to research, $30 \%$ of college freshman do not return for the second year. ${ }^{1}$ When on a campus where the college student perceives a strong institutional commitment to diversity, they report fewer issues with discrimination and bias. Going to college is more
Volume 2 Issue 3 - 2018

\author{
Reinard Valentine, Melissa Brevetti \\ Langston University, USA
}

Correspondence: Melissa Brevetti, Langston University, USA, Tel 405-623-3772, Email Melissa.a.brevetti-I@ou.edu

Received: April 06, 2018 | Published: May 03, 2018

than getting used to the classroom climate, but also getting adjusted to many different activities and events as they become prepared, involved, and adapted to the culture of higher education. Many students struggle with the pressure to prove themselves worthy of being on the yard, due to the fact that they feel left out of the equation. It would be very beneficial for colleges and universities to include cultural and socio-economic support systems on their respective campuses. ${ }^{1}$ It would be a worthy requirement that all areas, such as admissions and recruitment, student life, and student affairs, work together to review their campus climate in order to identify areas that need improvement.

\section{Language: promoting communication and success}

Insofar as novice identity engenders enthusiasm and curiosity, one significant hindrance within higher education includes uncertainty with language. All students have entered higher education with some criteria showing PK-12 mastery, but, most interestingly, students are unprepared for the rigor of hearing and learning new academic vocabulary in content areas. Despite increased access to traditional writing centers, resource librarians, and writing centers, students are underserved when it comes to clear expectations and direct support as communicated from professors. In large lecture hall classes, students are unlikely to ever talk face-to-face with their professors in order to understand the class goals and learning objectives. The learners can, of course, read the syllabus and get a vague notion of the overview of the class. And yet, many syllabi provide unclear purposes of the class due to the theoretical language or specific words used by particular professors/scholars, by carefully considering the struggles that novice students have with language, a little reflection goes a long way. In fact, the purpose of language is to share relevant information. When students are not doing well, we as professors should try to ask ourselves, "How can I deconstruct all this information?" When students are engaged, we as professors should try to ask ourselves, "How are these conditions allowing students to understand and participate?" Learning is a social process, so the company which we keep, including mentors and professors, become negative or positive influences.

\section{Desirable difficulty: getting uncomfortable}

In this classic framework of teaching, desirable difficulty Bjork ${ }^{3}$ relies on a balance of students evaluating previous knowledge with new, challenging objectives. Professors have to consider how much, 
including non-content skills, is new information so that students are not over-stimulated, which could be viewed as exploring the curriculum with one new component each time. Learning does not need to be viewed as linear. Sometimes, concepts may need to be visited again, or some objectives may need little practice time, as long as the curriculum is aligned each time to fulfill clear expectations for the students. Furthermore, learning should consist of spaced opportunities to study material for more than one assessment-in particular, professors providing ways for re-studying or supplementary projectsleads to improvements in long-term memory retention, Rowland. ${ }^{4}$ These inclusive practices include allowing time and space for students to explore content with personal creativity, finding ways to not just replicate the standard thinking of the alleged experts. As students see and use the material in different ways, they develop autonomy.

\section{Inclusive practices for advancement}

Learning is a life-long process. Although school assignments and projects have deadlines, the learning should continue. When students learn challenging concepts, they have to get uncomfortable-taking risks and missing the mark at times. Learner-centered or studentcentered environments are key to achieving desirable difficulty, because professors have to find out which objectives students understood and/or what level of mastery. Here are five principles to promote-with consistency-for all students:

a. Students need time and opportunity to grapple with the material. A learning objective should be interwoven throughout the course, because if a lack of spacing in the curriculum exists, that will lead to forgetting a one-time concept. It is critical to keep making connections and allowing time to re-study and to evolve the framework, especially as presented in the syllabus and key questions.

b. Examples are great tools for an initial idea while encouraging creativity. The sample student work that is shown should be viewed as a springboard so that the current students can take ownership of their ideas. The goal is to push students to be uncomfortable in which they are thinking, using, connecting, questioning, and evaluating material in a brand-new way.

c. All students have a preferred way of learning, so professors are responsible to use multiple ways that provide understanding of the topics and language. Visual aids, outlines, analogies, technology, hands-on design, group discussions, and reflections are just a few ways that I implement the language and allow them time to use the language, too.

d. If the word is an important concept and/or key term of the course, then special attention should be given to it. These literacy skills provide the springboard for more complex thinking.

e. Struggles are necessary, creating space and time to grapple with meanings are beneficial for growth. However, struggles should have prompt, effective feedback, which is also a critical piece of educators' responsibilities. Decades of research studies show that high expectations and positive interactions during this phase will lead to success. ${ }^{5-8}$ Moreover, the increased level of language will instill confidence in the learners.

\section{Conclusion: thinking about the past, thinking for the future}

In order to build global competitiveness, higher education offers the unique, positive opportunity for experiences and encounters with diverse groups of people. These inclusive practices are necessary to evolve thinking for the future. Thus when practices go wrong or well, we have to reflect upon not only the actions but the strategic thinking which led to failure or success in that situation. Frequently, however, early failures lead to progress if time is allowed. Our framework of inclusive practices is process-oriented, as we move forward to innovate new ways of seeing and acting, in addition to reasoning. The past can offer even more than insights and reflections toward a better future since inclusive practices uplift diverse people-who are encouraged regardless of race, gender, social class, education, sexual orientation, disability-to seek educational excellence in authentic ways. Finally, students' backgrounds and cultures should be honored, which we can achieve by helping students understand both our actions and their own, giving opportunities to respect and to learn across differences. Therefore, to produce both global and ethical people, higher education must aim for an equitable and inclusive education.

\section{Acknowledgments}

None.

\section{Conflict of interest}

The Author declares there is no conflict of interest.

\section{References}

1. US Department of Education. Advancing Diversity and Inclusion in Higher Education: Key Data Highlights Focusing on Race and Ethnicity and Promising Practices. 2016.

2. Lynch M. Diverse conversations: Why curriculum diversity is a good plan. 2016.

3. Bjork R. Memory and metamemory considerations in the training of human beings. In: Metcalfe J, Shimamura A, editors. Metacognition: Knowing about knowing. Cambridge, MIT Press; 1994:185-205.

4. Rowland CA. The effect of testing versus restudy on retention: A meta-analytic review of the testing effect. Psychological Bulletin. 2014;140(6):1432-1463.

5. Baxter G, Bowers J. Beyond self-actualization: the persuasion of Pygmalion. Training and Development Journal. 1985;39(8):69-71.

6. Daragh M, Clifton C, Garavan T, et al. The Pygmalion effect reconsidered: its implications for education, training and workplace learning. Journal of European Industrial Training. 1999;23(5):238-250.

7. Rosenthal F, Jacobsen S. Pygmalion in the classroom: Teacher expectation and pupils' intellectual development. New York: Holt, Rinehart, \& Winston; 1968.

8. Wang Y, Lin L. Pygmalion effect on junior English teaching. Advances in Language and Literary Studies. 2014;5(6):18-23. 